\title{
PEMBERDAYAAN MASYARAKAT MELALUI PENINGKATAN KUALITAS PENDIDIKAN, KESEHATAN DAN EKONOMI DI DESA LEUWISADENG
}

\author{
Septy Achyanadia ${ }^{1}$, Tri Wahyuni, Siti Nurjannah ${ }^{2}$ \\ septy.achyanadia@uika-bogor.ac.id \\ Dosen Fakultas Keguruan dan Ilmu Pendidikan ${ }^{1}$, Mahasiswa KKN Kelompok 65 Tahun \\ $2018^{2}$
}

\begin{abstract}
ABSTRAK
Kuliah kerja nyata (KKN) merupakan bagian kecil dari pemberdayaan masyarakat. Pemberdayaan masyarakat adalah untuk meningkatkan kemampuan dan kemandirian masyarakat dalam meningkatkan taraf hidupnya. Tujuan kegiatan pemberdayaan ini adalah untuk membentuk individu dan masyarakat menjadi mandiri. Perlunya upaya pemberdayaan adalah berangkat dari kenyataan masih lemahnya posisi sebagian besar masyarakat dalam menuntut hak dan menjalankan kewajibannya yang ditunjukkan dengan kurangnya akses pendidikan, kesehatan dan ekonomi yang ada diwilayah tersebut. Pendidikan adalah usaha sadar dan terencana untuk mewujudkan suasana belajar dan proses pembelajaran agar peserta didik aktif dalam mengembangkan potensi Kecerdasan, akhlak mulia dan ketrampilan lain yang diperlukan masyarakat. Upaya dalam meningkatkan kesadaran akan pentingnya kesehatan adalah dengan melakukan penyuluhan kepada masyarakat akan pentingnya hidup sehat. Dalam meningkatkan taraf ekonomi yaaitu dengan memberikan penyuluhan mengenai pentingnya kewirausahaan agar dapat menambah kreatifitas masyarakat dalam meningkatkan nilai tambah usaha dalam permodalan.
\end{abstract}

Kata Kunci: Pemberdayaan Masyarakat, Pendidikan, Kesehatan, Ekonomi

\section{PENDAHULUAN}

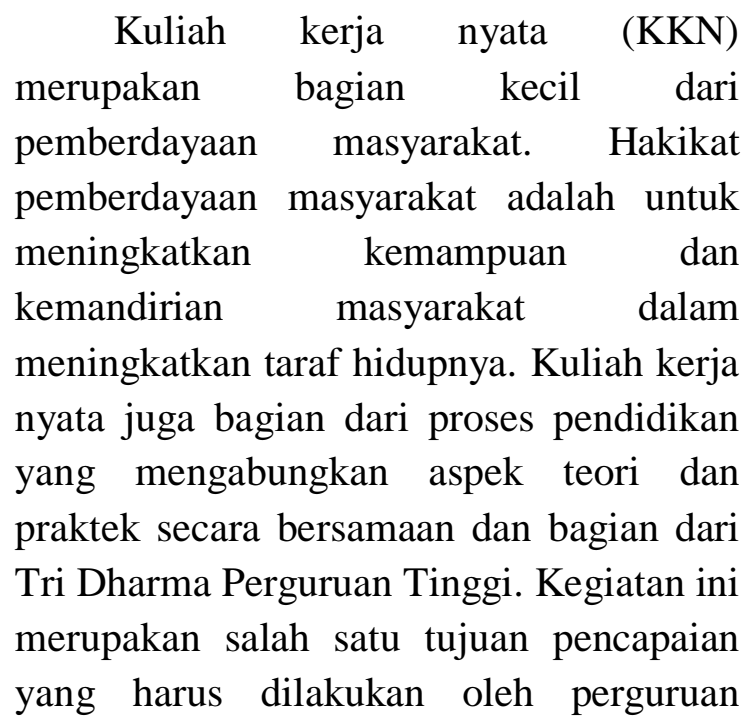

tinggi. Tujuan lain dari KKN ini adalah menempatkan mahasiswa di luar kampus agar mahasiswa hidup ditengah-tengah masyarakat bersama masyarakat memanfaatkan potensi sumber daya alam lokal dan sumber daya manusia yang ada untuk mengatasi permasalahan masyarakat dalam kurun waktu tertentu. Kuliah kerja nyata dituntut untuk melahirkan orangorang yang memiliki semangat tinggi dan memiliki pemikiran yang kritis, kreatif, mandiri, Inovatif dan tujuan lainnya yaitu untuk mencapai akselerasi dan efektifitas dalam program pembangunan masyarakat.Terkait dengan tujuan 
pemberdayaan, Sulistiyani (2004) menjelaskan bahwa tujuan yang ingin dicapai dari pemberdayaan masyarakat adalah untuk membentuk individu dan masyarakat menjadi mandiri. Kemandirian tersebut meliputi kemandirian berpikir, bertindak dan mengendalikan apa yang mereka lakukan.

Konsep Pemberdayaan pada perkembangannya memiliki banyak definisi yang dikemukakan oleh para ahli yang memiliki komitmen tinggi terhadap usaha memajukan kesejahteraan masyarakat, seperti yang dikemukakan oleh Ife (1995 182), yaitu pemberdayaan berarti menyiapkan kepada masyarakat berupa sumberdaya, kesempatan, pengetahuan, dan keahlian untuk meningkatkan kapasitas diri masyarakat di dalam menentukan masa depan mereka, serta untuk berpartisipasi dan mempengaruh kehidupan dalam Komunitas masyarakat itu sendiri.

Perlunya upaya pemberdayaan adalah berangkat dari kenyataan masih lemahnya posisi sebagian besar masyarakat dalam menuntut hak dan menjalankan kewajibannya ditunjukkan dengan kurang aksesnya mereka terhadap beberapa fasilitas, misalnya informasi, Pendidikan, permodalan usaha, hukum, dan kesehatan Berbagai kelemahan akses tersebut diawali dengan rendahnya tingkat pendidikan yang dimiliki oleh masyarakat kita terutama di pedesaaan yang ada di Kp Babakan Gunung Wiru Rt 05/07, Desa Leuwisadeng, Kec Leuwisadeng Kab Bogor.

\section{Kondisi Geografis}

Desa Leuwisadeng adalah salah satu desa diwilayah kecamatan leuwisadeng, Kabupaten Bogor. Kecamatan
Leuwisadeng mempunyai luas wilayah 3.532,54 hektar Berikut ini batas wilayah:

\begin{tabular}{|c|c|c|}
\hline NO & ARAH & BERBATASAN \\
\hline 1 & Utara & Sibanteng \\
\hline 2 & Barat & Pabangbon \\
\hline 3 & Selatan & Sadengkolot \\
\hline 4 & Timur & Cibeber 1 dan II \\
\hline
\end{tabular}

\section{Kondisi Masyarakat}

Jumlah Penduduk Desa Leuwisadeng Sampai Tahun 2014 tercatat Sebanyak 73.705 jiwa sebagai berikut:

\begin{tabular}{|r|c|c|c|}
\hline TAHUN & LK & PR & JUMLAH \\
\hline 2012 & 37.364 & 34.110 & 71.474 \\
\hline 2013 & 37.475 & 34.465 & 71.940 \\
\hline 2014 & 38.387 & 35.318 & 73.705 \\
\hline
\end{tabular}

\section{EKONOMI}

Desa Leuwisadeng merupakan salah satu desa yang berada di wilayah Kecamatan Leuwisadeng, Kabupaten Bogor. Latar belakang pendidikan di desa ini sebagian besar lulusan Sekolah Dasar (SD), Namun tak sedikit juga yang melanjutkan ke pendidikan yang lebih tinggi, Pendidikan tertinggi hanya sampai Bangku Sekolah Menengah Atas (SMP). Dikarenakan Mayoritas Penduduk Leuwisadeng memiliki mata pencaharian Petani, Pedangan, Buruh, Pegawai negeri dan lainnya. Perlu diketahui bahwa penduduk desa Leuwisadeng memiliki nilai relegius yang sangat tinggi, hal ini dibuktikannya dengan banyaknya Pondok pesantren yang ada di wilayah leuwisadeng dan Masyarakat juga memiliki kefahaman ilmu agama. Setiap seminggu dua kali diadakannya pengajian disetiap RT yaitu Pengajian ibu-ibu atau bapak-bapak yang dilaksanakan setiap hari Rabu dan Jumat. Secara umum kondisi Sosial dan politik 
serta ketentraman dan ketertiban di wilayah desa Leuwisadeng Khususnya di KP. Babakan Gunung Wiru aman dan terkendalikan. Mengenai masalah kesehatan masih harus diperhatikan dikarenakan masih ada yang membuang sampah sembarang.

\section{Permasalahan Yang dihadapi}

Kp. Babakan Gunung Wiru desa leuwisadeng menurut Analisis SWOT yang dilakukan oleh Kelompok 65 meliputi 4 Aspek:

a. Pendidikan,di Kp.Babakan Gunung Wiru pendidikan kurang perhatian dari masyarakat,pendidikan paling tinggi sampai tingkat sekolah menengah Atas karena rendahnya tingkat pendidikan masih banyak pernikahan di usia dini. Dalam pembelajaran Masih kurangnya tenaga guru yang professional,sarana prasarana dalam proses pembelajaran masih minim. Selain itu juga masih Kurangnya Kesadaran pada masyarakat akan pentingnya pendidikan

b. Keharmonisan, di Kp. Babakan Gunung Wiru desa Lewisadeng menurut hasil wawancara dengan warga, bahwa masih adanya pertengkaran dan masih banyak perceraian yang tidak resmi menggunakan surat.

c. Ekonomi, di Masyarakat Kp.Babakan Gunung wiru akses pemasaranan yang masih pasif. sebagian besar masyarakat memiliki mata pencaharian Petani, pedagang dan pegawai swasta maupun negeri. Masih lemahnya tingkat ekonomi di desa leuwisadeng dikarenakan Kurangnya kreatifitas dan inovasi dalam mengembangkan SDA yang ada, usaha paling besar yaitu warung sembako.

d. Lingkungan Hidup, di Kp.Babakan Gunung Wiru kesadaran akan lingkungan sehat masih kurang, masih ada warga yang membuang sampah sembarangan dan bahkan masyarakat membuang sampah dikali, dipinggir jalan dan sekitar rumah. Hal ini disebabkan karena tidak adanya tempat pembuangan sampah dan ada sebagian warga yang masih menggunakan MCK umum 


\section{METODE PENGABDIAN}

Tahap pelaksanaan untuk kegiatan ini sebagaimana terlihat pada bagan sebagai berikut:

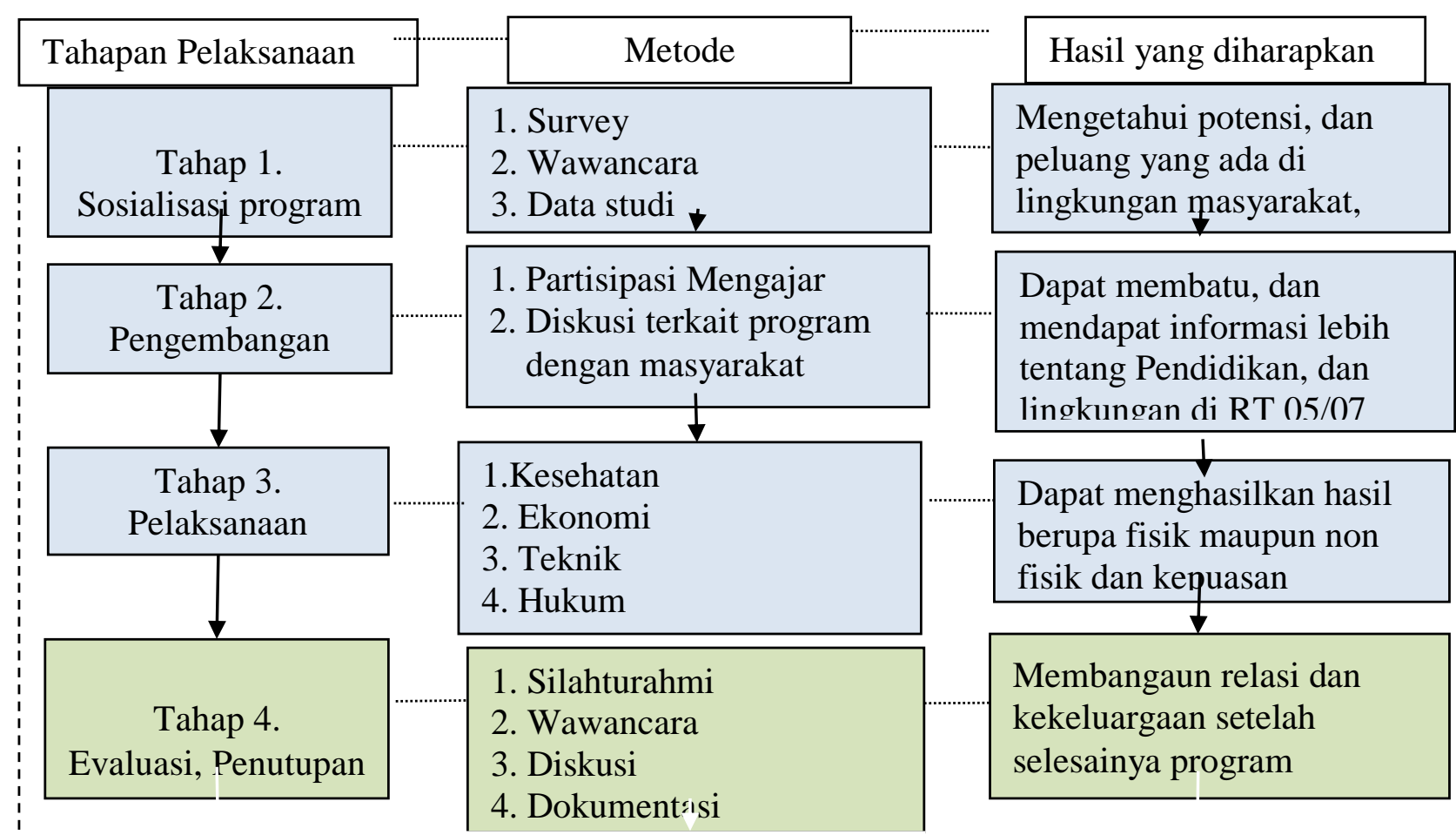

Jadwal Kegiatan

\begin{tabular}{|c|l|c|c|c|c|}
\hline \multirow{2}{*}{ No. } & \multicolumn{1}{|c|}{ Kegiatan } & \multicolumn{3}{c|}{ Minggu } \\
\cline { 3 - 5 } & \multicolumn{1}{|c|}{} & \multicolumn{1}{|c|}{$\mathbf{1}$} & $\mathbf{2}$ & $\mathbf{3}$ & $\mathbf{4}$ \\
\hline 1 & Sosialisasi Rencana Kegiatan & & & & \\
\hline 2 & Penyusunan Rencana Kegiatan & & \\
\hline 3 & $\begin{array}{l}\text { Partisipasi mengajar disekitar Lingkungan } \\
\text { (Paud, TPA, Bimbel, Pengajian, KF, SDN Agra } \\
\text { Puri dsb) }\end{array}$ & & & \\
\hline 4. & Pembuatan MCK dan Tempat Sampah & & & \\
\hline 5. & Jalan Sehat & & & \\
\hline 5 & Pembuatan Gapura 17 Agustus & & & \\
\hline 6 & Acara Lomba 17 Agustus & & & \\
\hline 7 & Posyandu & & & \\
\hline 8 & Peunyuluhan Menabung Sejak Dini & & & \\
\hline 9 & $\begin{array}{l}\text { Penyuluhan Cara mencuci tangan yang baik dan } \\
\text { benar }\end{array}$ & & & \\
\hline
\end{tabular}




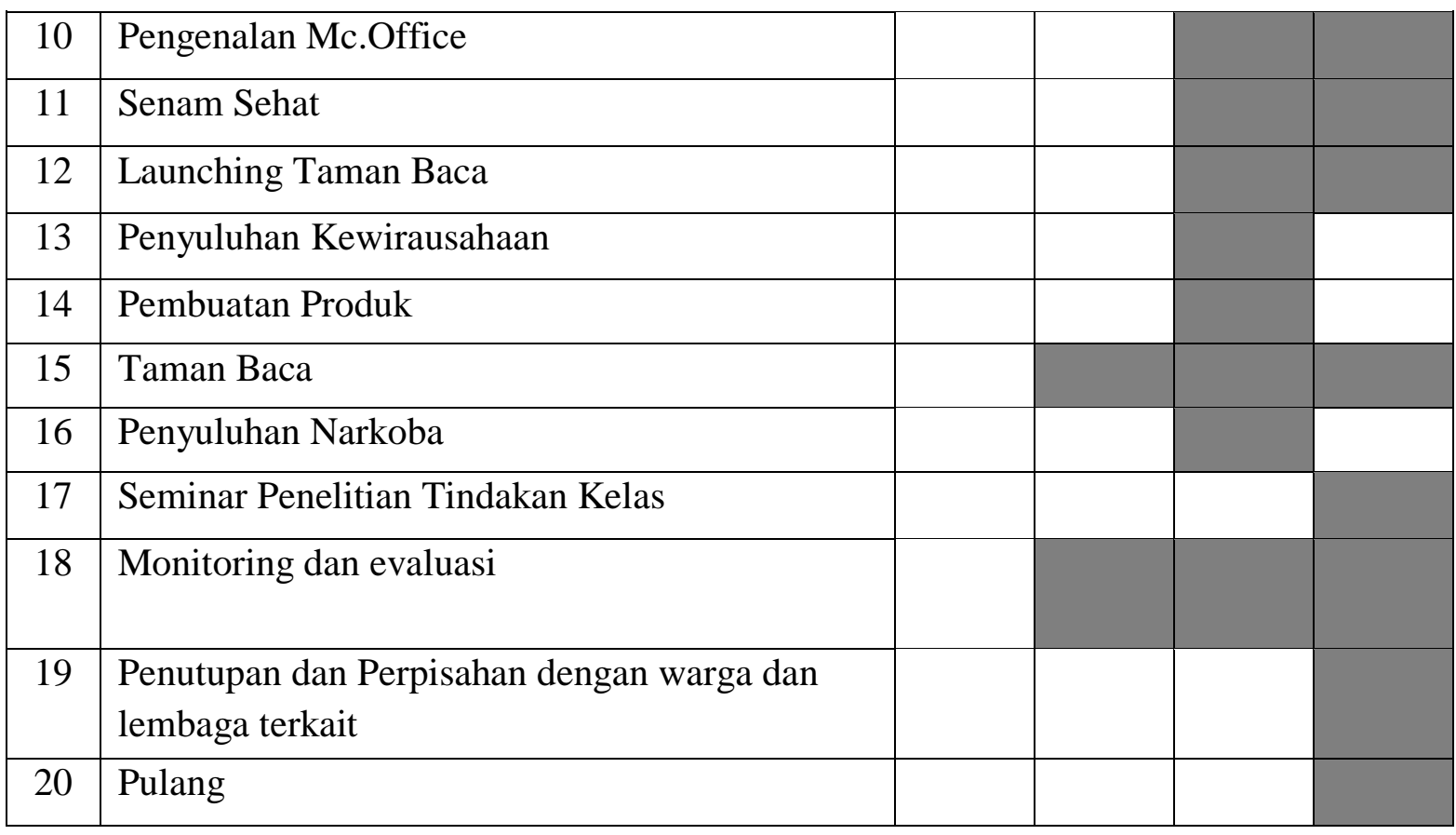

\section{Metode Pendekatan}

Pendekatan yang digunakan pada kegiatan ini adalah dengan pendekatan geografi sosial, dimana pendekatan ini terdiri dari 3 aspek: (1) Keruangan, (2) Kelingkungan, dan (3) Kompleks Wilayah. Ketiga aspek tersebut dilihat dari sudut pandang geografi untuk menganalisis dan bagaimana solusi untuk kehidupan sosial masyarakat desa Kp.Babakan Gunung Wiru. Maka diperlukan strategi dalam pelaksanaanya dengan beberapa pendekatan yang strategis, diantaranya:

a. Pendekatan berdasarkan karakter masyarakat, yakni pembinaan yang dilakukan akan disesuaikan dengan karakter masyarakat. Joyce dan Weil (1996) mengungkapkan bahwa model pendidikan yang relevan dengan perilaku sosial dan nilai adalah dengan banyak memberikan permainan peran. Hal ini dilakukan untuk memberi pengalaman riil kepada peserta didik tentang sesuatu yang dilakukan atau dirasakan oleh orang lain. Memang, dalam prakteknya, tidak seluruh aspek harus menggunakan permainan ini.
Dalam beberapa hal, terdapat kegiatan-kegiatan yang hanya golongan tertentu untuk melakukannya. Sejalan dengan konsep Joyce dan Weil, cooperative learning yang digagas Slavin (2005) dapat digunakan untuk membangun kesadaran toleransi masyarakat. Hal ini karena penekanan dari konsep pendidikan ini adalah kerjasama yang merupakan urat nadi toleransi.

b. Pendekatan organisasi, yaitu pendekatan dimana sebagian kegiatan diorganisir dan bekerja sama dengan lembaga pendidikan dan lembaga masyarakat yang ada di desa leuwisadeng.

c. Pendekatan Relegius, yaitu pendekatan yang menggunakan nilainilai agama sebagi basis dari kegiatan, karena pada beberapa program kerja ada yang dilaksanakan di majslismajlis ta'lim yang dimana sasarannya adalah ibu-ibu atau bapak-bapak, sehingga dalam setiap kegiatan dihubungkan dengan kegiatan unsur keagamaan. 
d. Pendekataan Kekerabatan, artinya bahwa pembinaan yang dilakukan senantiasa dikaitkan dalam rangka meningkatkan kesadaran akan pentingnya pendidikan, kesehatan dan kreatifitas.

\section{REALISASI PROGRAM}

Dalam Pelaksanaan kegiatan KKN Tematik Terinetgrasi Universitas Ibn Khaldun Bogor kami selaku kelompok 65, yang ditempatkan di desa Leuwisadeng kecamatan leuwisadeng, Tepatnya berada di Kp. Babakan Gunung Wiru Rt 05/07 kami membuat beberapa rangkaian program kerja yang alhamdulillah berjalan lancar sesuai dengan rencana, Adapun Pogram-pogram yang sudah terealisasikan adalah sebagai berikut;

Bidang Pendidikan, pada bidang pendidikan program yang kami laksanakan ini bertujuan untuk meningkatkan semangat dan motivasi belajar masyarakat setempat akan pentingnya pendidikan kerena tidak ada cara lain kecuali melalui meningkatkan mutu pendidikan.

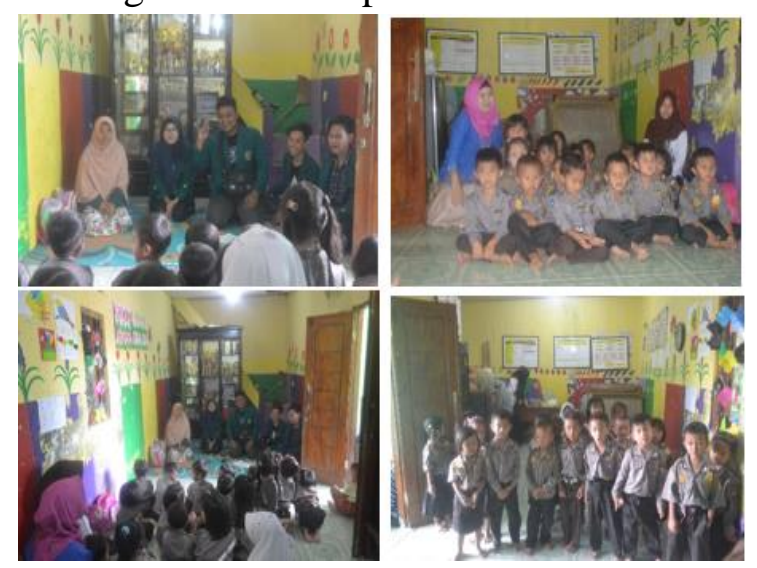

Mengajar di Paud

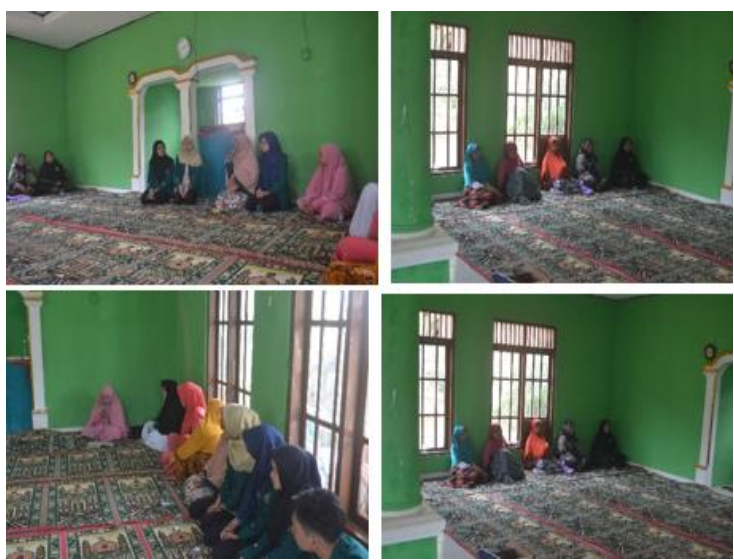

Mengikuti Pengajian Rutin di Majlis Nurul Hidayah

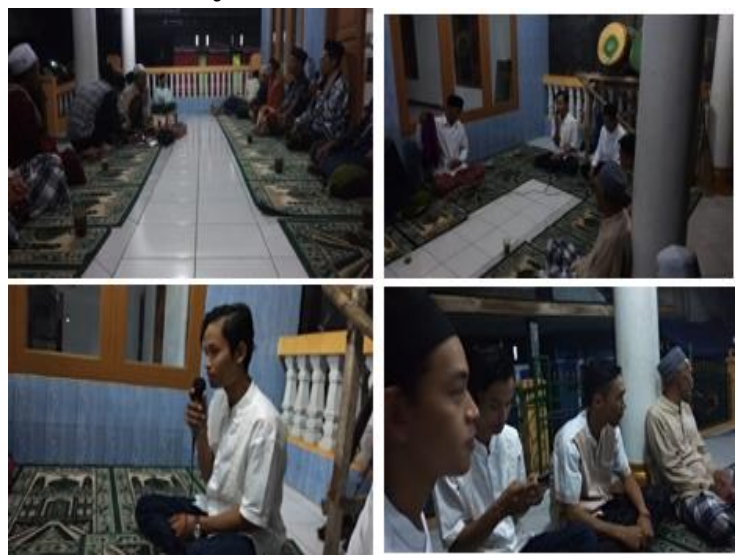

Pengajian bapak-bapak di Majelis Nurul Hidayah

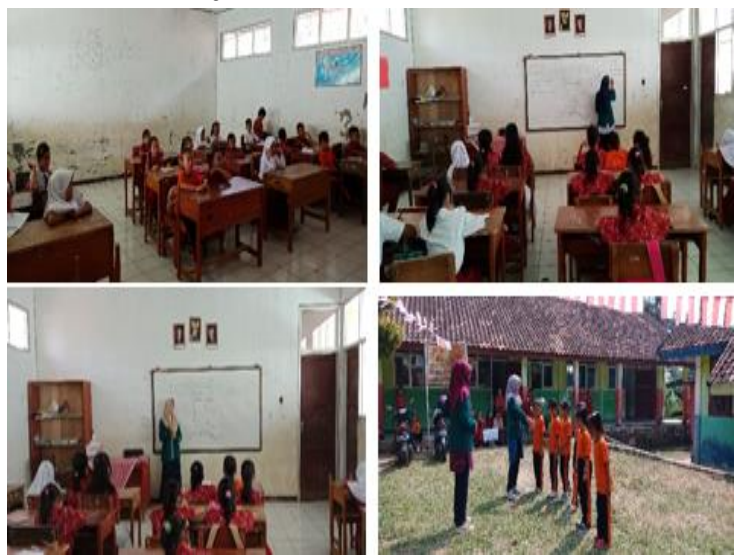

Mengajar Pramuka di SDN Arga Puri 


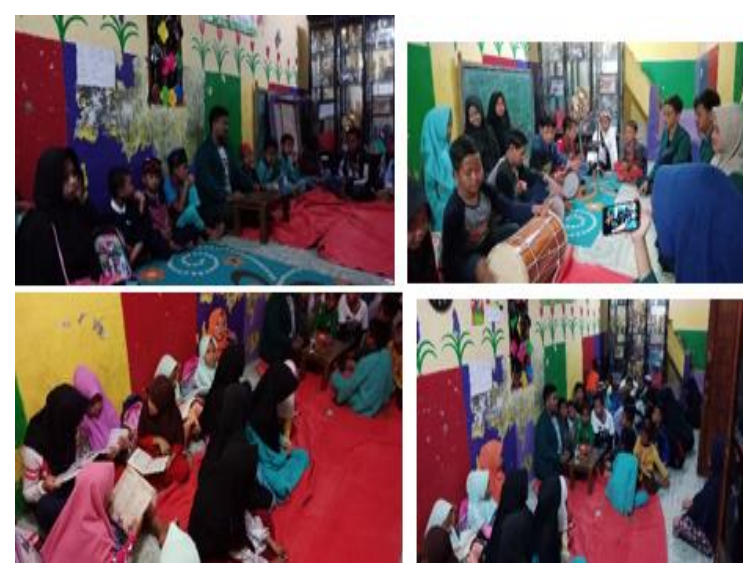

Mengajar TPA Nurul Iman dan TPA di Majelis Hidayah

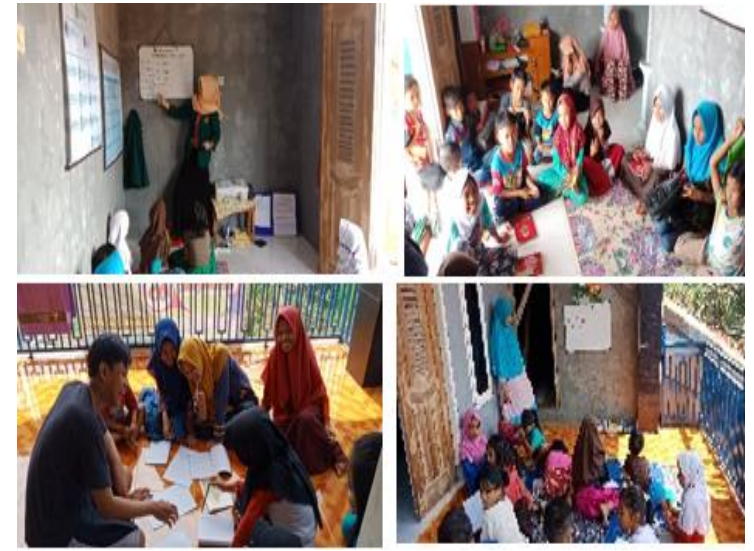

Mengajar Bimbel (Bahasa Ingris,Bahasa Arab dan Matematika)

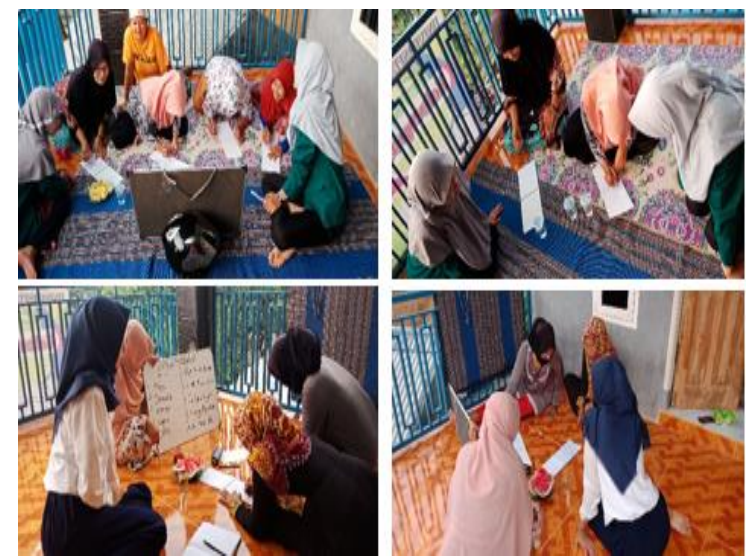

Keaksaraan Fungsional

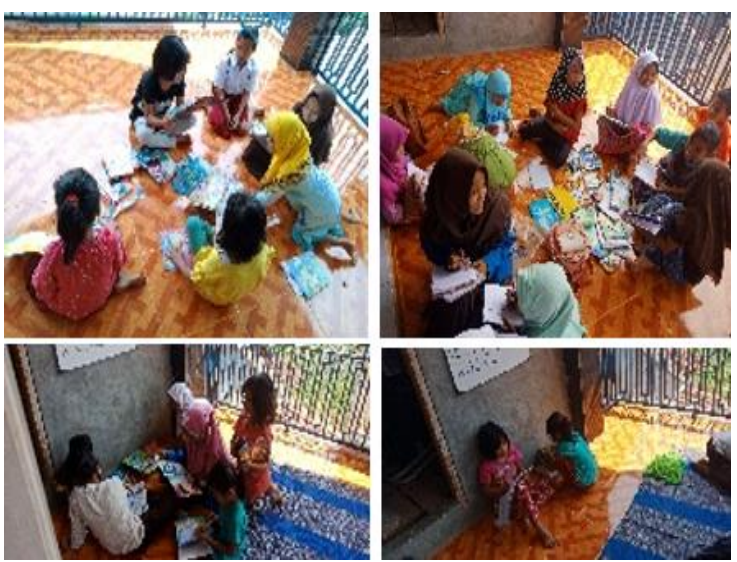

Taman Baca Masyarakat (TBM)

TBM merupakan salah satu wadah yang bergerak dibidang pendidikan yang mempunyai tujuan untuk meningkatkan kembali minat baca masyarakat tanpa membedakan status sosial, adat istiadat, tingkat pendidikan dan lain sebagainnya. Program ini, dilaksanakan oleh bidang pendidikan setiap hari Sabtu dan Minggu bertempatkan di Posko.

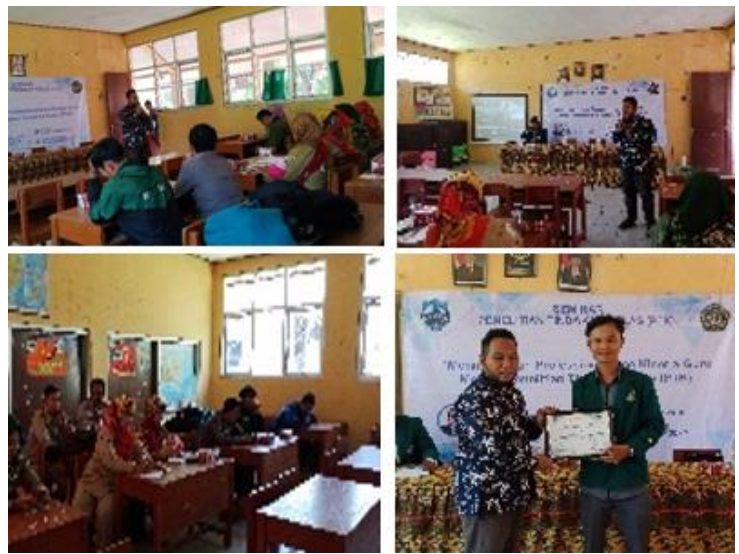

\section{Seminar Penelitian Tindakan Kelas}

Seminar PTK yang kami laksanakan yang bertemakan Meningkatkan Professionalitas Kinerja guru melalui PTK. Menurut Suyanto (1997) tujuan dari Penelitian Tindakan Kelas ini adalah Meningkatkan dan/atau memperbaiki praktik pembelajaran disekolah, meningkatkan relevansi pendidikan, meningkatkan mutu pendidikan dan efisiensi pengelolaan pendidikan. 


\section{Bidang Kesehatan}

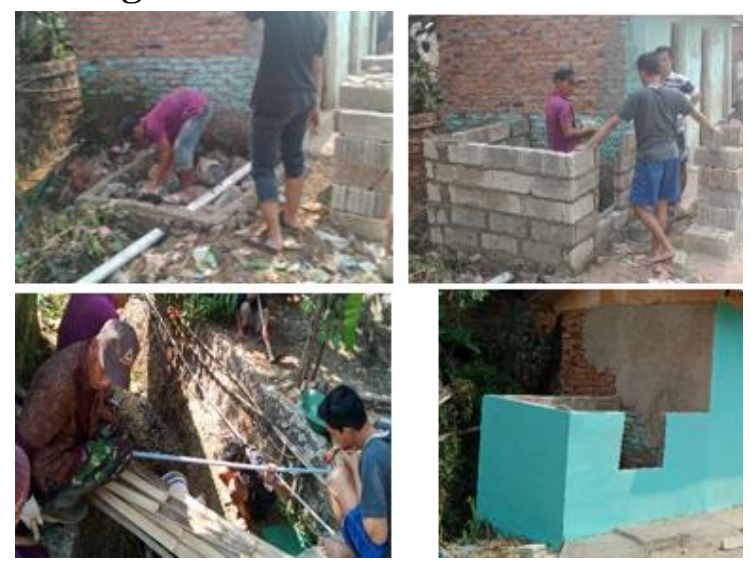

Pembuatan Bak Sampah

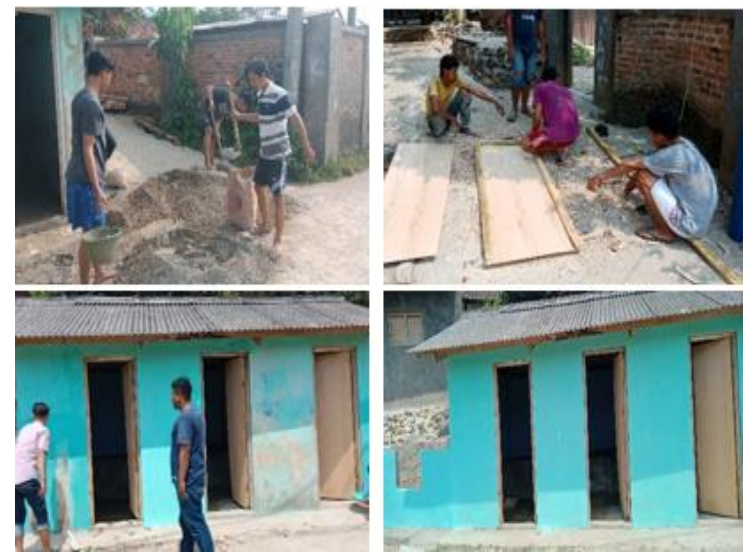

\section{Perbaikan MCK}
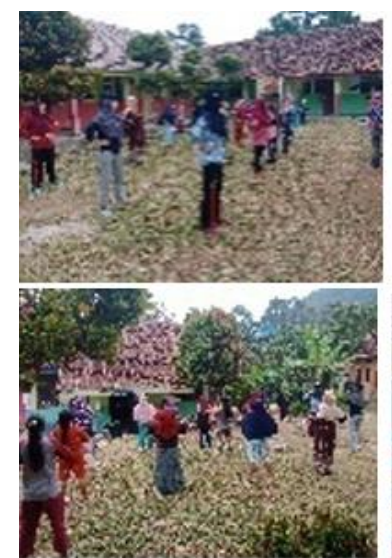

Senam Pagi

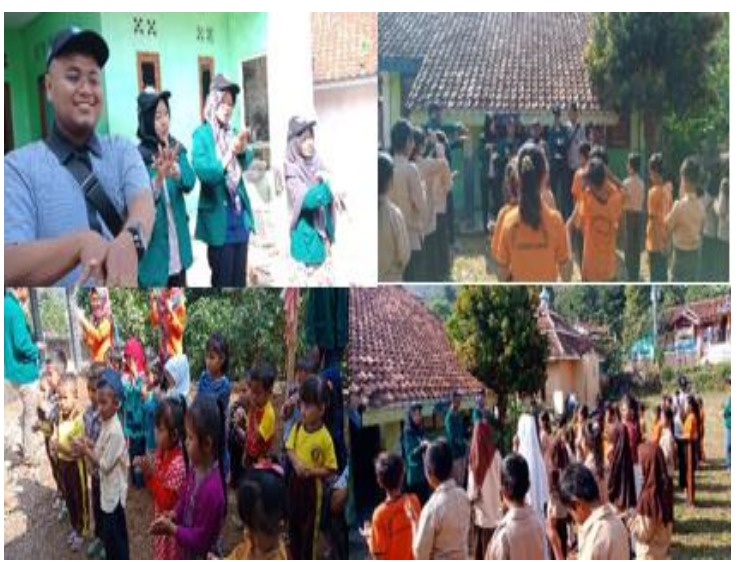

Penyuluhan Cara mencuci tangan yang baik dan benar

Kami melaksanakan penyuluhan tentang pentingnya mencuci tangan pada hari jum'at tanggal 24 Agustus memberikan pengarahan kepada siswa-siswi kelas 1,2,3,4,5 dan 6 di SDN Agra Puri. Dengan tujuan agar meereka mengetahui pentingnya menjaga kebersihan dan juga agar mereka mengetahui pentingnya mencuci tangan sebelum dan sesudah makan. Dan kami pun memberikan beberapa hadiah kepada siswa-siswi yang bisa mempraktekkan kembali langkah cara mencuci tangan yang baik dan benar yang telah disampaikan.

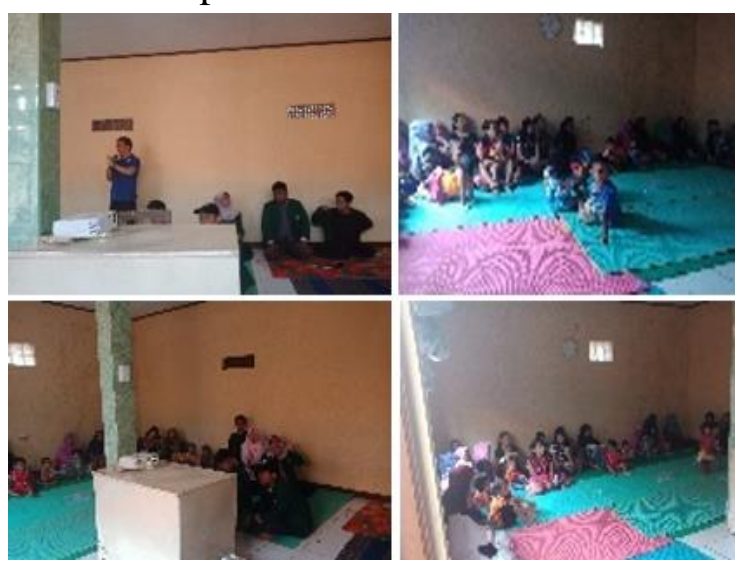

Bidang Ekonomi (Penyuluhan

Kewirausahaan) 


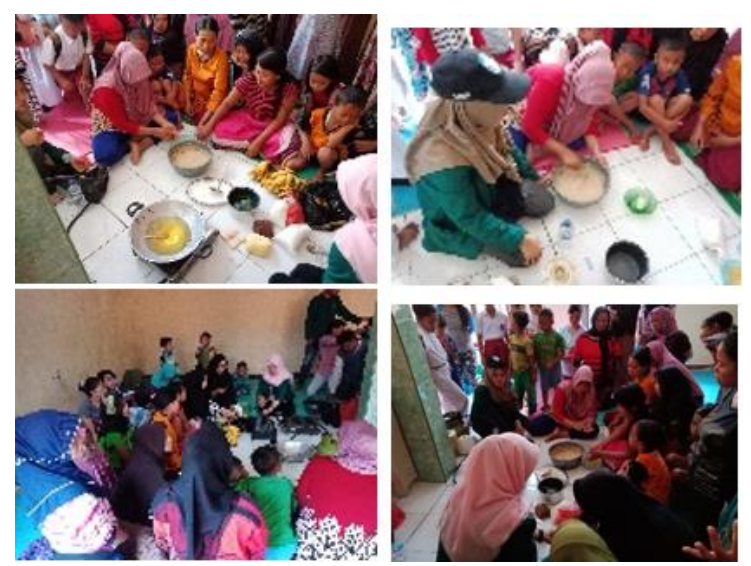

Pembuatan Produk

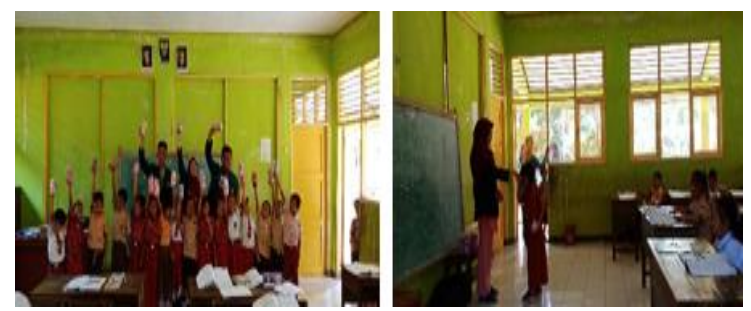

\section{Penyuluhan Menabung Sejak Dini}

Kami melaksanakan penyuluhan gemar menabung sejak dini dengan memberikan pemaparan kepada siswa-siswi kelas 1-2 SDN Arga Puri. agar bisa menabung atau menyisihkan uangnya dengan menabung, memberikan penjelasan tentang seberapa penting menanamkan budaya menabung sejak dini.

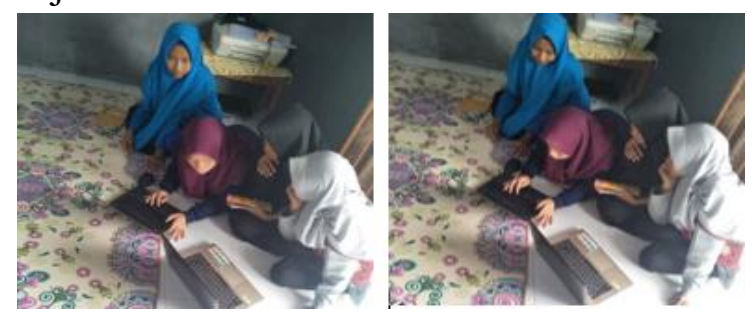

Bidang Teknik (Pengenalan Ms. Office)

Pelatihan komputer merupakan sebuah wadah yang berfungsi untuk menjembatani siswa/siswi yang mengalami kesulitan dalam mengoperasikan komputer, mengingat pendidikan masa kini telah berbasis tegnologi maka sangat diharapkan masyarakat mampu menguasai cara kerja komputer.
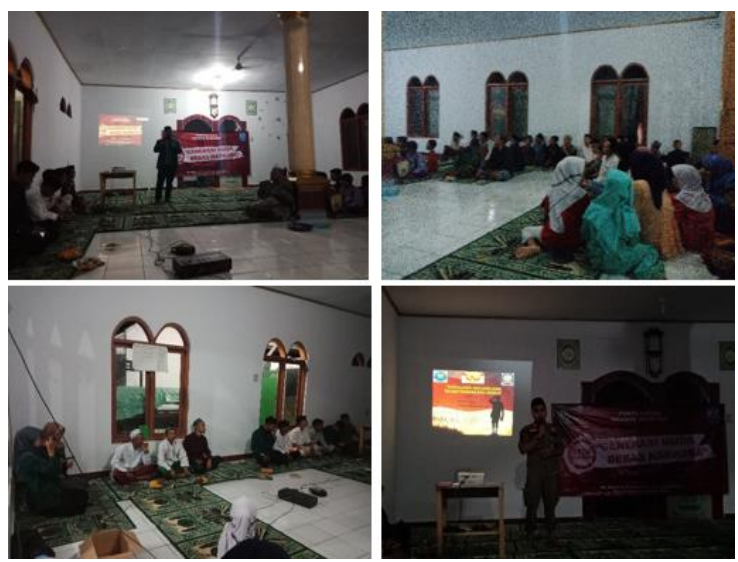

Bidang Hukum (Penyuluhan tentang

Bahaya Narkoba)

Pelaksanaan penyuluhan Bahaya Narkoba dilaksanakan pada hari Rabu dan memberikan materi mereka mengetahui bagaimana dampak yang akan terjadi akibat narkoba juga memberikan pengarahan bagaimana seharusnya pemuda pintar dalam memilih pergaulan agar terhindar.

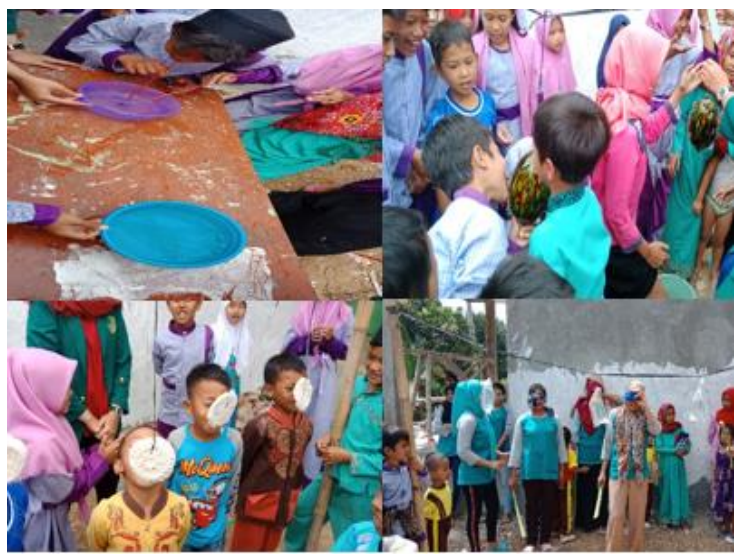

\section{Partisipasi kegiatan 17 agustus}

Partisipasi dalam perayaan HUT RI, Tanggal 17 Agustus merupakan hari istemewa bagi bangsa Indonesia, untuk memperingati hari kemerdekaan dan menumbuhkan rasa Nasionalisme dan Patriotisme diadakannya berbagai kegiatan perlombaa sebagai rasa syukur kita sebagai bangsa. Adapun tujuan dari perlombaan itu adalah sebagai sarana edukasi, Kreatifitas dan meningkatkan rasa Nasionalisme terhadap bagsa Indonesia. 


\section{KESIMPULAN}

Dari hasil program kegiatan yang telah dicapai selama melaksanakan Kegiatan Kuliah Kerja Nyata (KKN) dapat memberikan dampak yang signifikan bagi masyarakat khusunya di Kp. Babakan Gunung Wiru desa leuwisadeng kecamatan leuwisadeng. Kuliah Kerja Nyata (KKN) merupakan sarana bagi mahasiswa untuk menyalurkan potensinya sebagai agen perubahan. Peran Mahasiswa yang mampu melakukan berbagai aksi untuk menjadi bagian dari agen perubahan (Agent of chage) yang signifikat terhadap desa yang dijadikan objek KKN. KKN yang dilaksanakan oleh kelompok 65 bertempat di kp.Babakan Gunung Wiru desa Leuwisadeng kecamatan leuwisadeng kabupaten Bogor. Pelaksanaannya berawal pada tanggal 7 Agustus sampai 5 September 2018.

a. Program yang dilaksanakan selama KKN terdiri dari 5 Bidang diantaranya adalah Bidang Pendidikan dan Agama, Kesehatan, Ekonomi, Teknik dan Hukum.

b. Bidang Pendidikan, memberikan semangat dan motivasi kepada anakanak kp.Babakan Gunung wiru dalam belajar baik ilmu agama maupun ilmu umum,Selain itu pogram bimbel yang memiliki tujuan dalam meningkatan Skill berbahasa yaitu meliputi bahasa Ingris dan bahasa Arab selain itu juga menambah Informasi, wawasan yang luas mengenai dunia pendidikan.

c. Bidang Kesehatan

Dapat memberikan manfaat kepada masyarakat dalam meningkatkan penyadaran pentingnya menjaga kesehatan dan hidup yang sehat.

d. Bidang Ekonomi
Memberikan ilmu mengenai pentingnya kewirausahaan dan informasi mengenai pentingnya berwirausaha dan memberikan demonstrasi cara membuat Pisang Nuget yang enak dan berkualitas. Sehingga dapat menambah kreatifitas masyarakat dalam meningkatkan nilai tambah usaha dalam permodalan.

e. Bidang Teknik

Meningkatkan Skill dalam mengoperasikan Perangkat computer dan mampu menambah kemampuan dalam bidang teknologi informasi

f. Bidang Hukum

Masyarakat setempat mendapatkan informasi mengenai bahaya narkoba bagi kesehatan dan bagaimana narkoba dalam pandangan islam.

g. Terealisasinya Program pengabdian kepada masyarakat yang dilakukan oleh mahasiswa dalam rangka mewujudkan program Universitas Ibn Khaldun Bogor sesuai dengan visi dan misi Ibn Khaldun Bogor. Dan erbentuknya kerja sama langsung antara masyarakat setempat dengan mahasiswa.

h. Meningkatkan kepedulian terhadap masalah yang dihadapi masyarakat, turatama dalam kegiatan Lingkungan hidup,Masyarakat sangat senang sekali karna adanya perbaikan MCK dan Tempat pembuangan sampah, karena selama ini masyarakat kebingungan dalam menyelesaikan pembuang sampah dan Masalah MCK juga teratasi dengan baik

i. Partisipasi dalam kegiatan 17 Agustus dapat menumbuhkan rasa Nasionalisme kita terhadap bangsa Indonesia dan sebagai rasa syukur. Selain itu juga sebagai saran edukasi dan kreatifitas bagi anak bangsa utuk lebih inovasi dan menumbuhkan rasa patriotisme. 


\section{SARAN}

Berdasarkan Kegiatan yang telah dilaksanakan oleh mahasiswa KKN kelompok 65 Universitas Ibn Khaldun Bogor yang dilaksanakan di desa leuwisadeng Kp.Babakan Gunung Wiru Rt 05/07, Kecamatan Leuwisadeng kabupaten Bogor,Kami selaku Peserta KKN memberikan Rekomendsi beberapa hal sebagai saran untuk kegiatan selanjutnya:

1. Perlu adanya kerja sama dan dukungan yang baik dari perangkat desa setempat dengan masyarakat dalam rangka meningkatkan segala potensi di desa leuwisadeng dalam meningkatkan kesejahteraan hidup masyarakat.

2. Perlu adanya dukungan dari perangkat desa dalam menjamin kesehatan dan kebersihan masyarakat

3. Perlunya dukungan akan Pentingnya pendidikan bagi masyarakat setempat

4. Saling bekerjasama para pihak terkait,baik dinas pendidikan,pihak swasta ,pemerintahan dan juga kesadaran diri dari masyarakat.

5. Perlu adanya dukungan moral atau moril yang lebih dari aparat desa setempat dalam meningkatkan kesejahteraan masyarakat

6. Perlu adanya dukungan dalam meningkatkan kreatifitas masyarakat dalam mengolah SDM yang ada

7. Harus mampu merelaisasikan progampogram khusunya pendidikan,ekonomi dan kesehatan.

\section{REFERENSI}

Rosyadi R dan Eska P.P.2018. Petunjuk Pelaksanaan KKN Tematik Terintegrasi 2018. Bogor: UIKA Pres
Kabupaten Bogor. Kondisi Geografis dan wilayah desa leuwisadeng. 2018. http://kecamatanleuwisadeng.bogork ab.go.id/index.php/multisite/pge/110 $\underline{0}$.

lfe, Jim.(1996). Strategi Pemberdayaan Masyarakat. Bandung: Humaniora Utama Press.

Artikel Seminar Penelitian Tindakan Kelas. https://silabus.org/pengertian pendidikan/. 10 September 2018

lfe,Jim.(1996). Strategi Pemberdayaan Masyarakat. Bandung: Humaniora Utama Press.

Prasetya, E.P, Abdulrahman, Rahmania f. 2018. Pemberdayaan Masyarakat Tentang Kesehatan, Pendidikan Dan Kreatifitas 02(01) : 11-13. Jurnal Abdos

Nasution Andreanda, Rokatul U, Basit A.2017. Pemberdayaan Masyarakat desa Gunung Mulya dengan 4 Program Bidang kerja. 01(01) : 9. Jurnal Abdos

Gustiawati, Syarifah, Awaludi A, Nur F A. 2017. Terciptanya Masyarakat yang Beriman,Sehat,Produktif dan Kreatif di Desa Ciseeng 01(01) : 103-104. Jurnal Abdos

Suwarno, Setiadi. 2017. Pemberdayaan Masyarakat Mandiri, Sehat dan berwawasan Lingkungan Melalui Program KKN di Desa Curahtakir Kabupaten Jember. Universitas Jember. 